\title{
Hurdles in the Transformation of Peace Process: Indicators for Universities in Pakistan
}

\author{
* Farah Latif Naz, PhD Scholar (Lecturer) (Corresponding Author) \\ ** Khalid Khurshid, Professor \\ *** Javed Iqbal, Associate Profess or
}

\begin{abstract}

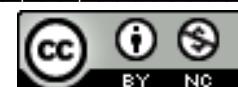

The present article represents the most operational and implacable indicators for the transformation of peace in the universities of Pakistan. The main objective of the study is to find out the major hurdles that educational institutions are facing in the way of the development peace culture. Furthermore, this study provides the highlights for the peace development in the universities. The qualitative analysis was used to collect the opinions of the respondents. For this purpose, a semistructured interview was designed for the public university heads/chairman of different social sciences departments. Moreover, the data were analyzed with NVIVO that used for the in-depth thematic analysis and presents in the form of a word cloud (MADQDA 18). The study findings, however, show that the universities are facing different dimensions that are related to teacher competency, student behaviors, and social influences. The study further recommended, that according to the indicators there is a need to plan flexible and operational strategies to overcome the hurdles that are creating unrest in the educational institutions, there is space to work on teachers and students relationship, develop moral and valued based class environment and involve students in creative and productive activities for the peaceful setting in the present phenomena.
\end{abstract}

Keywords: Hurdles, Peace Process, Indicators, Transformation, Universities

Introduction

The educational institutions are responsible for shaping behaviors and develop the overall character building of the individuals. In this context, universities are the main source that transforms the behaviors of individuals. The positive change in the behaviors of the youth further works significantly in the social communities within the country. Therefore, the educational settings need to promote harmony and integrated concepts for the learners. While Ahmar (2018) addressed that the contribution of the universities is most important in the innovation and creative development this reduce the conflicts and develop negotiation skills among the students. The changing role of universities involved the overall moral and personality development of the learner with the ability of critical and creative thinking participates in the social welfare of the country (El-Jardali, 2018).

In the view of Waldmuller et al., (2019) the sustainable peace transformation required overall human development, education is the combination of skills, knowledge, and attitudes, the systematic involvement of these factors in the educational institutions, especially universities bring revolutionary change. Furthermore, Shah (2021) stated that there is a very strong relationship between the transformation of any concept and the role of the teachers. The motivational behaviors developed by the change agents play a significant role in the acceptance of different cultures within similar settings. Education further is a transformational activity for the individuals, particularly this provides the backbone for the survival of the citizens in the society.

Furthermore, Rieckmann (2017) elaborated that education is the key factor for uplifting any domain in society, the main elements of the universities are to train the future leaders and develop desirable skills in them. The understanding of justice, morals, and value-oriented behaviors. Sanaullah (2021) and Yousaf (2021) discussed the role of civilians and the influence of different cultural tribes in Pakistan. The historical perspectives of the cultural norms are associated with the roots of their behaviors. Moreover, this situation needs to address the sustainable transformation of peace culture in the universities.

\footnotetext{
* Department of Education, Bahauddin Zakariya University Multan Email: farahlatif@bzu.edu.pk

** Department of Education, Bahauddin Zakariya University, Multan Email: khalidkhurshid@bzu.edu.pk

*** Department of Education, Ghazi University Dera Ghazi Khan Email: javed.edu2020@ gmail.com
} 
Maurya (2018) and Bakar (2018) mentioned that the role of higher education towards the change is most demanding, there is a need to understand the operational strategies for the desired results. The combinations of culture, religion, ethnic values, and different perspectives required dialogue skills. The universities develop and transform these skills among individuals (Valenzuela, 2019). The value of the peace development process acknowledged with the empirical evidence that related to the UNESCO and UN peace keeping programs, the contribution of sustainable development goals further take part in every spheres' of life (Bergman et al., 2018).

Moreover, Amadei (2021) pointed out that the sustainable peace nexus developed with the use of resolving the different challenged that institutions are facing, the culture is the crucial indicator in the process of peaceful transformation. Therefore, Montiel (2018) observed that peace transformation is associated with social transformation, social activities, and different cultural movements linked with educational settings. The violence and conflicts are situated in the societies; education is the key factor that works for creating a peaceful and balanced culture in the community (Ferguson, 2018). As Chaleta et al., (2021) indicated that for achieving sustainable goals universities need to establish different potentials in the courses of university education. The realization of selfaccountability enhanced the overall environment. In addition, Paletta and Bonoli (2019) have also noted that education in universities follows the United Nations given agenda for peace development.

\section{Research Objectives}

1. To identify the hurdles in the transformation of the peace process in the universities.

2. To suggest suitable indicators for the development of peace in the universities.

\section{Research Question}

1. What are the hurdles in the transformation of the peace process in the universities?

2. What are the suitable indicators for the development of peace in the universities?

\section{Methodology/ Research design}

This study is based on qualitative analysis and further explains that analysis in descriptive and explanatory form. The qualitative techniques used to assess the behaviors. In this study design, explore the university heads/chairman opinions and perceptions that are related to transforming peace culture in the universities. Moreover, explore the leadership experiences regarding prevailing situations in the educational sectors.

\section{Population \&Sampling technique}

The population of the study was all the head/Chairman (male and female) of different social sciences and Language and Arts departments. According to HEIs (Higher Education Institutions), there are sixty-seven (67) universities in Pakistan. In which twenty-two (22) universities in Punjab province, from the twenty-two (22) universities for this study eighteen (18) universities have the Social Science disciplines in their institutions, with the help of convenient sampling two (02) districts (Multan and Bahawalpur) were selected for collecting the qualitative data. Afterthought, four (04) Public sector universities, two (02) (Bahauddin Zakariya University and Woman University) from Multan, and two (02) (The Islamia University and The Sadiq Women University) from Bahawalpur were selected by convenient sampling technique. At the last step, eighteen (18) heads of different social sciences departments were selected with convenient sampling from the four (04) selected universities of Punjab.

\section{Research instruments}

For collecting the data a semi-structured interview was developed that consisted of six (06) questions, the interview questions were noted, recorded, and observed individually. This technique was useful for gaining maximum response of the respondent's attitudes and believes that are related to current situations. The interviews were taken from the 4 universities that were selected through convenient sampling from southern Punjab.

\section{Data analys es techniques}

The data was analyzed with the help of the thematic analysis technique (NVIVO), the opinions of the respondents were tabulated in the shape of different themes of the word frequency table, and further, these word themes were analyzed with the help of word cloud. The thematic hub of words organized with the help of (MAXQDA 18) that presents the comprehensive presentation of the respondents' opinions in the word cloud. This technique was provided the word depiction of the opinions that are related to the thematic framework. 


\section{Qualitative Analysis}

\section{Question 1:}

What is the situation of intolerance in the universities? The collected responses are tabulated according to word cloud.

Table 1: Situation of intolerance in the universities

\begin{tabular}{lll}
\hline Reasons & Frequency & Percentage \% \\
\hline Social Media & 3 & 7.14 \\
Power Grouping & 3 & 7.14 \\
Cultural influence & 4 & 9.52 \\
Lack of awareness & 3 & 7.14 \\
Discrimination in class & 3 & 7.14 \\
Students background & 10 & 23.81 \\
Class level & 5 & 11.90 \\
Teachers behaviors & 5 & 11.90 \\
Political influences & 3 & 7.14 \\
Education environment & 3 & 7.14 \\
\hline Total & $\mathbf{4 2}$ & $\mathbf{1 0 0}$ \\
\hline
\end{tabular}

Figure 1: Situation of intole rance in the universities

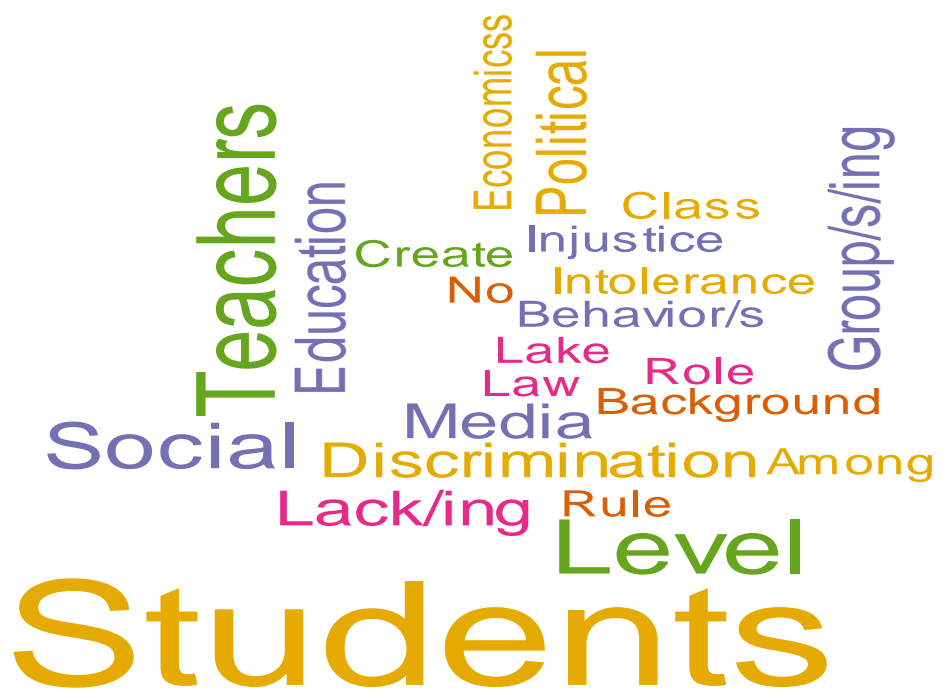

The above table shows that intolerance in universities is the main cause or hurdle in the peace process in educational institutions, the table, and word count indicated that the highest factor related to the students' background $(23.81 \%)$ after that class or financial levels $(11.90 \%)$ also affect the peace progress, moreover, the cultural influences and teacher behaviors $(9.52 \%)$, furthermore, all the respondents agreed that the peace process is related with the change in the internal behaviors of the teachers and related persons.

Question 2:

This question demonstrated the current obstructions that are making obstacles for the maintainable harmony improvement in the universities. The most basic variables were summed up as underneath,

Table 2: Obstacles for the sustainable peace development

\begin{tabular}{lll}
\hline Hurdles & Frequency & Percentage \% \\
\hline Lake of social behaviors & 8 & 40.00 \\
Teachers negative attitude & 5 & 25.00 \\
External Powers & 3 & 15.00 \\
Unaware about Peace culture & 4 & 20.00 \\
\hline Total & $\mathbf{2 0}$ & $\mathbf{1 0 0}$ \\
\hline
\end{tabular}


Figure 2: Word cloud of obstacles for the sustainable peace development

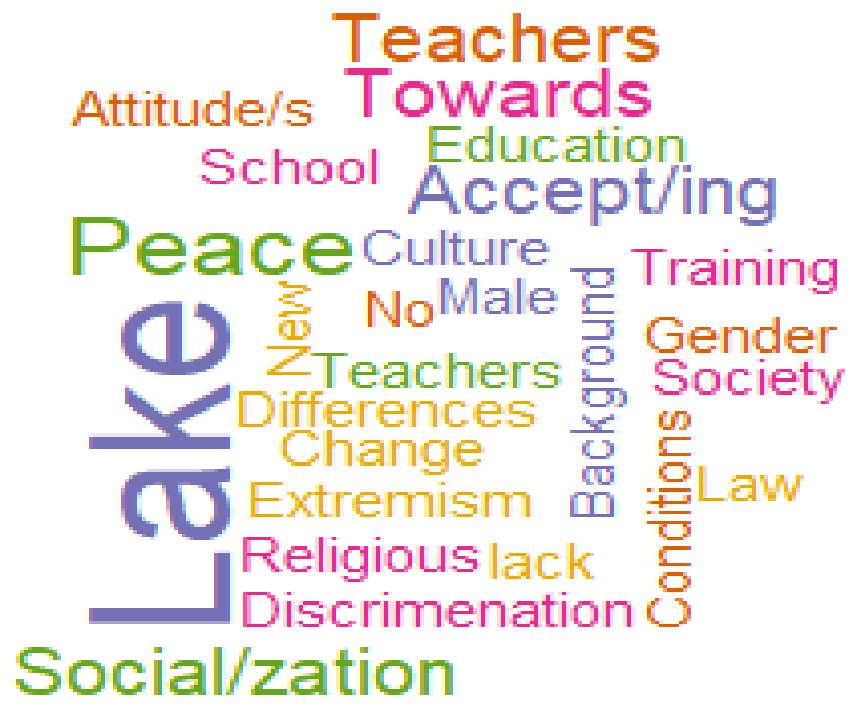

The above table 2 uncovered that most powerful obstacles that are faced in the development of peace culture in the universities of Pakistan, high pool of socialization, this is (40\%) that shows that the pool of socialization related with the pool of segregation, pool of regard towards contrasts and pool of ethics these interrelated terms are the significant hindrances for harmony making measure in the universities, further, acknowledgment of peace culture have $(20 \%)$ word checks which implies that there is need to create acknowledgment of various societies among students and preparing of the people for the acknowledgment of various societies required the consideration of the educators and organizations, it was seen by the assessments of the respondents that to give greatest expectations towards the social and civic character working of the university students in which such countless things are remembered for term of communication, moral development of events and the general day by day schedules these efforts accommodating for the advancement positive attitude for the change of peace culture.

\section{Question 3:}

This question investigates the methodologies that ought to be received to advance peace and resistance in university students. The techniques recommended by the head of departments had been summed up as beneath,

Table 3: Ope rational strate gies to de velop peace

\begin{tabular}{lll}
\hline Strategies & Frequency & Percentage \% \\
\hline Innovative activities & 5 & 8.47 \\
Promotion of Peace concept & 5 & 8.47 \\
Creativity work & 3 & 5.08 \\
Teacher behavior & 8 & 13.56 \\
Role of Ideals & 4 & 6.78 \\
Moral Training & 4 & 6.78 \\
Value orientations & 3 & 5.08 \\
Course/Interesting & 4 & 6.78 \\
Peace/concept & 4 & 6.78 \\
Training for peace & 4 & 6.78 \\
Student Training & 8 & 13.56 \\
Motivational works & 3 & 5.08 \\
Workshops/seminars & 4 & 6.78 \\
\hline Total & $\mathbf{5 9}$ & $\mathbf{1 0 0}$ \\
\hline
\end{tabular}


Figure 3: Word cloud about the operational strategies to de velop peace

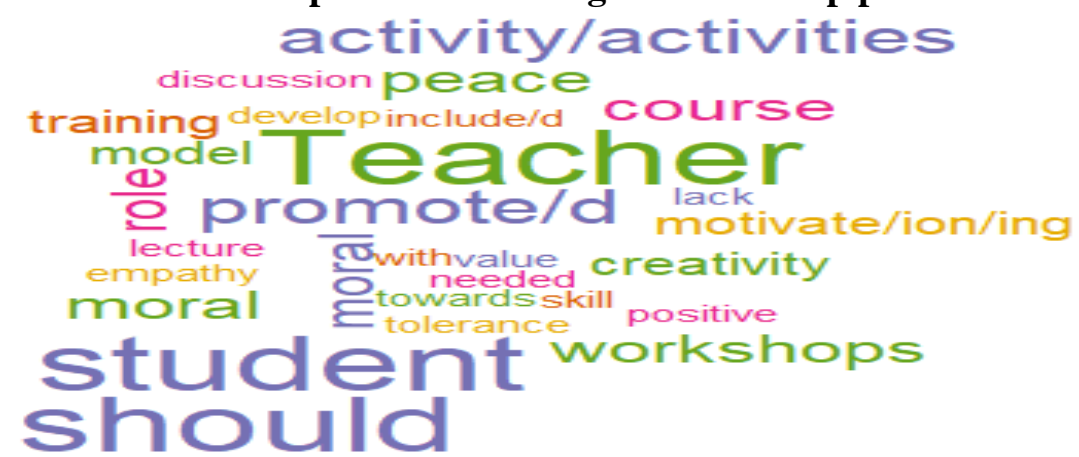

Table 3 demonstrated the assessments of the respondents in term of various word considers the most noteworthy word mean the procedures to advance peace culture in the university are instructor and students training that is $(13.56 \%)$, the dominant part of the respondents agreed that various kinds of the training are required for the students and educators, these trainings are connected with the qualities trainings, moral training and motivational exercises about the culture of peacerelated issues. These are useful for the advancement of peaceful culture in the universities. Further, generally, respondents additionally had an assessment that creativity workshops and talks on peace likewise be the part of the course.

Question 4:

This segment discovers the difficulties faced by the country for creating manageable peace culture at university climate. These difficulties are summed up in the given recurrence table and word cloud.

Table 4: Challenges in Pakistan for the developing of a peaceful culture

\begin{tabular}{lll}
\hline Challenges & Frequency & Percentage \\
\hline Countries influence/neighbor & 3 & 9.68 \\
Economic condition & 4 & 12.90 \\
Lake of interest & 3 & 9.68 \\
Unemployment & 4 & 12.90 \\
Injustice & 4 & 12.90 \\
Job Uncertainty & 3 & 9.68 \\
Current Situation/Satisfaction & 3 & 9.68 \\
Cultural Extremism & 4 & 12.90 \\
Less developed behaviors & 3 & 9.68 \\
\hline Total & $\mathbf{3 1}$ & $\mathbf{1 0 0}$ \\
\hline
\end{tabular}

Figure 4: Word cloud of challenges in Pakistan for the de veloping of a peaceful culture

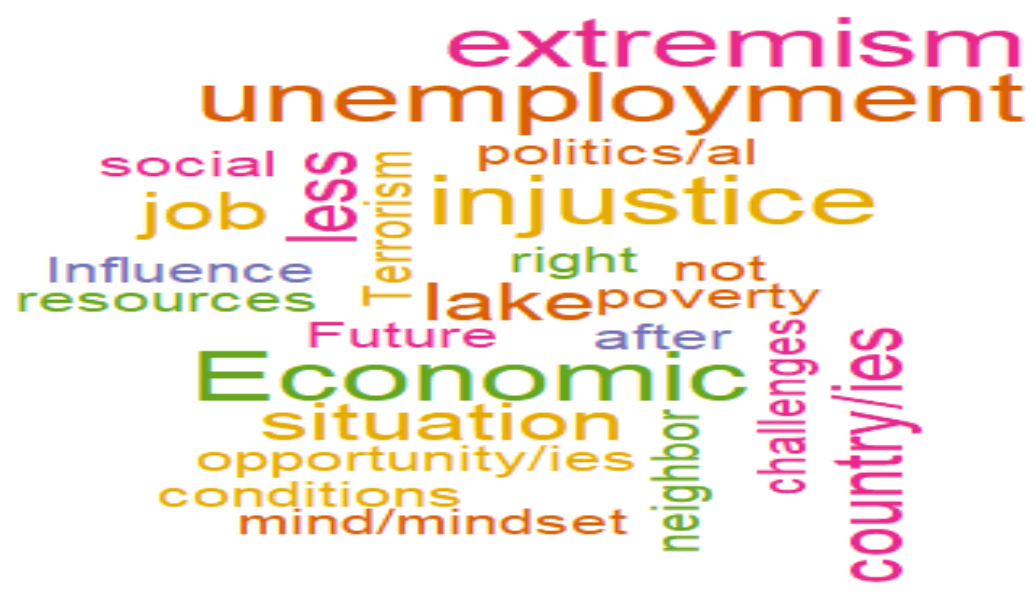

The above words cloud and recurrence both depicts the assessments of the respondents from this it was seen that significant difficulties looked by the country for creating peace culture in university climate were connected with the economic condition $(12.90 \%)$, joblessness $(12,90 \%)$, bad form $(12.90 \%)$ and radicalism $(12.90 \%)$. Roughly $13 \%$ recognized these four significant difficulties looked at by Pakistan for creating a peaceful culture in the universities. Further, the respondents were proposed that with the execution of equity in the administrative level and the departments in term of 
severe guidelines are also useful for peace then the serene circumstance can build the making of the positive habits and behavior by the educators.

Question 5:

This question was identified with the measures taken by university departments for advancing peace culture. The outcomes summed up in the given recurrence table and word cloud,

Table 5: Activities in the departments for promoting peace in youth

\begin{tabular}{lll}
\hline Adopted Strategies & Frequency & Percentage \\
\hline Healthy Games & 3 & 8.82 \\
Cultural programs & 3 & 8.82 \\
Moral Training & 4 & 11.76 \\
Healthy participations & 3 & 8.82 \\
Other activities & 5 & 14.71 \\
Seminars by scholars & 4 & 11.76 \\
Workshops & 4 & 11.76 \\
Educational Trips & 3 & 8.82 \\
Peace Competitions & 5 & 14.71 \\
\hline Total & $\mathbf{3 4}$ & $\mathbf{1 0 0}$ \\
\hline
\end{tabular}

Figure 5: Word cloud related to activities in the departments for promoting peace in youth

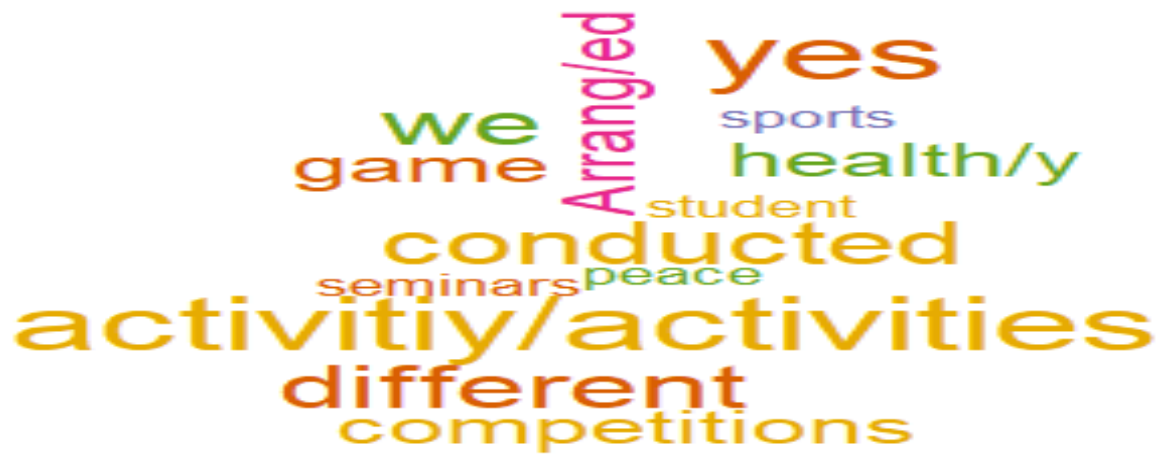

Table 5 gives the data about the various procedures that university departments were received for the advancement of peace culture, the various heads of the departments have various sentiments towards the techniques, the absolute first system is connected with the various exercises $(14.71 \%)$ were embraced by the departments for advancing the peace among students, these exercises are connected with, discussions, composing and diverse game competitions few departments have designed these exercises of an on and a portion of the departments were arranged consistently, just as there were $(11.76 \%)$ respondents utilized different methodologies that are connected with the various sorts of training, courses and workshops for the students and instructors to the attention of peace. Around (9\%) departments pay attention to games, competitions, healthy exercises, and excursions to create positive attitudes in the students' behavior.

Question 6:

This question was connected to the implementing indicator for the SDGs to change of peace culture in the universities. The assessments were summarized in the following recurrence table and word cloud.

Table 6: Indicators to implement SDGs for peace culture in the universities

\begin{tabular}{lll}
\hline Suggestions & Frequency & Percentage \\
\hline Teacher competency & 7 & 14.29 \\
Involvement of Youth & 9 & 18.37 \\
Peace Engagements & 3 & 6.12 \\
Positive activities/Harmony & 5 & 10.20 \\
Overall Grooming & 9 & 18.37 \\
Workshops on values & 3 & 6.12 \\
Seminar on morals & 4 & 8.16 \\
Positive knowledge Vs Negative skills & 4 & 8.16 \\
Peace talks Vs dialogue skills & 5 & 10.20 \\
\hline Total & $\mathbf{4 9}$ & $\mathbf{1 0 0}$ \\
\hline
\end{tabular}


Figure 6: Word cloud of Indicators to implement SDGs for peace culture in the universities

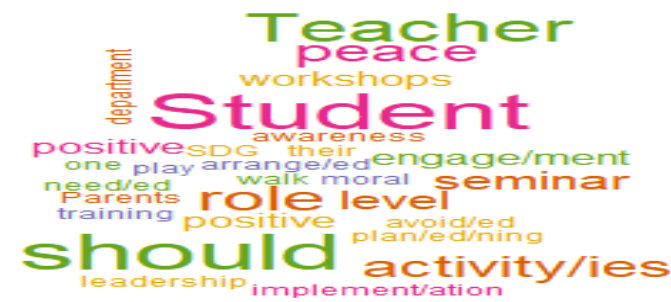

Table 6 clarified the general assessments of the respondents for the execution of SDGs and change of peace culture in the universities, it was seen that significant ideas given by the university department heads that toward the advancement of peace culture and further for the execution of SDGs (Sustainable Development Goals) need to work on the awareness projects, workshops and training for the students and educators, the part of instructors in educational institutions are at main concern and during the time spent change of peace culture and for the implementation process of SDGs, the encouraging learning climate address every one of the potential parts of the sustainable development. Roughly (18.34\%) ideas were identified with overall improvement of the students and (14.29\%) ideas were identified with the educator and students connection, the job of the instructor for the general advancement of the students is truly remarkable, in the idea of overall development every one of the perspectives that are connected with the attention to values, positive attitudes towards the tangled circumstance and the practical information and abilities are included.

\section{Discussion}

Results of the study showed that some different aspects and perceptions are facing the development of peace in the universities. From the findings of the study, the indicators pointed out that the policymakers need to address the present issues and resolved them within the circumstances. Moreover, the role of the leadership affect the overall structure of the institutions, this highlighted in term of administration and teachers as a leader in the class, furthermore, class is the platform where the next level generation developed, so the quality role of teacher and the behaviors of the teachers in the classroom build the creative minds or terrorist minds. Furthermore, Fisher et al., (2021) and Jamal (2021) in their work have the related results and indicators that also focused on the theatrical framework and more researches that elaborate the sustainable environment and explain various cultures in the class and some sort of workshops and seminars also motivate the students towards the culture of peace and harmony. In addition, Bragin et al., (2021) and Saeed (2021) have also argued in the study that the traditional instructional styles are are the obstacles in the implementation of the peace process in the public sector university. Moreover, Verwoerd (2019) in the study observed that the students are the agents of peace and structural change is possible with the youth's positive participation in the community. External power groups and political influences in the educational institutions need to control, furthermore, Ganesan (2019) expressed that the student groups and unions turned towards productive activities. The higher educational institutions have to provide multiple opportunities to the teachers and students for the transformation in their behaviors for the development of peace in the universities. The quality of education required lawful accountability for all the stakeholders. There are different studies conducted for peace development, as in the study of Karliani and Triyani (2020) observed that the behaviors of the young students are more influential, the trending needs are provided to the developed minds. Further, Kurian \& Kester (2019) have discussed that in the early ages the concepts of peace are associated with social values and behaviors, but in the youth, there is a need to construct the true standards of peace. Moreover, the changing attitudes of the individuals accept the change in the environment whether educational or social in a positive way (Tanyel \& Kiralp, 2021).

\section{Conclusion}

On the above analysis, this study found that there are different hindrances such as teacher-student relationships, lack of moral and ethical bonding in the classroom. Therefore, the present study suggested that to develop a peaceful culture in the universities there is a need to take operational actions and follow the suggested indicators. Moreover, the existing culture of the universities required attention to organize adequate planning to achieve the desired outcomes. In the concluded results, suggested that the indicators that are highlighted in this study be implemented accordingly. 


\section{Recommendations}

On the basis of the study, the following recommendations were listed,

1. There is a need to follow specific policies at the government and university levels for the transformation of peace at higher educational institutions.

2. Include moral and valued based education in the overall course outlines

3. The external influences on the universities should be managed with highly sincere leadership.

4. This study further extended to private universities and other higher educational institutions.

\section{References}

Ahmar, M. (2018). Peace and conflict management for sustainable development in Pakistan. Journal of South Asian and Middle Eastern Studies, 42(1), 49-66.

Amadei, B. (2021). A systems approach to the sustainability-peace nexus. Sustainability Science, 114.

Bakar, O. (2018). Cultural symbiosis and the role of religion in the contemporary world: An Islamic perspective. KATHA-The Official Journal of the Centre for Civilizational Dialogue, 4(1), 3158.

Bergman, Z., Bergman, M. M., Fernandes, K., Grossrieder, D., \& Schneider, L. (2018). The contribution of UNESCO chairs toward achieving the UN sustainable development goals. Sustainability, 10(12), 4471.

Bragin, M., Akesson, B., Ahmady, M., Akbari, S., Ayubi, B., Faqiri, R. \& Sediqi, S. (2021). Peace, love, and justice: A participatory phenomenological study of psychosocial well-being in Afghanistan. International Social Work, 0020872820969781.

Chaleta, E., Saraiva, M., Leal, F., Fialho, I., \& Borralho, A. (2021). Higher Education and Sustainable Development Goals (SDG)-Potential Contribution of the Undergraduate Courses of the School of Social Sciences of the University of Évora. Sustainability, 13(4), 1828.

Clayton, G., Dorussen, H., \& Böhmelt, T. (2021). United Nations peace initiatives 1946-2015: introducing a new dataset. International Interactions, 47(1), 161-180.

El-Jardali, F., Ataya, N., \& Fadlallah, R. (2018). Changing roles of universities in the era of SDGs: rising to the global challenge through institutionalizing partnerships with governments and communities. Health research policy and systems, 16(1), 1-5.

Ferguson, N., McDaid, S., \& McAuley, J. W. (2018). Social movements, structural violence, and conflict transformation in Northern Ireland: The role of loyalist paramilitaries. Peace and Conflict: Journal of Peace Psychology, 24(1), 19.

Fisher, J., Arora, P., Chen, S., Rhee, S., Blaine, T., \& Simangan, D. (2021). Four propositions on integrated sustainability: toward a theoretical framework to understand the environment, peace, and sustainability nexus. Sustainability Science, 1-21.

Ganesan, N. (2019). Democratization and Its Impact on Ethnic Conflict and Peace in Myanmar. In International Perspectives on Democratization and Peace. Emerald Publishing Limited.

Jamal, H. (2021). Proposed National Indicator Framework for SDG 4: The Case of Pakistan.

Karliani, E., \& Triyani, T. (2020). Strengthening student's peace-loving attitudes through human betting value-based general education curriculum. Journal of Human Behavior in the Social Environment, 1-12.

Kurian, N., \& Kester, K. (2019). Southern voices in peace education: interrogating race, marginalization and cultural violence in the field. Journal of peace education, 16(1), 21-48.

Maurya, P. (2018). Higher Education and Online Learning: Towards a Culture of Virtual Universities. Higher Education.

Montiel, C. J. (2018). Peace psychologists and social transformation: A Global South perspective. Peace and Conflict: Journal of Peace Psychology, 24(1), 64.

Paletta, A., \& Bonoli, A. (2019). Governing the university in the perspective of the United Nations 2030 Agenda. International Journal of Sustainability in Higher Education.

Rieckmann, M. (2017). Education for sustainable development goals: Learning objectives. UNESCO Publishing.

Saeed, R. A., Ahmed, R., \& Hussain, A. (2021). Role of Pakistani Universities in Interfaith Dialogue, Harmony and Relations an Index and Bibliometric of Produced Academic Dissertations. Library Philosophy and Practice, 1-27. 
Sanaullah. (2021). Civilians' survival strategies during the Taliban's insurgency (2007-9), Pakistan: a look at the consequences. Small Wars \& Insurgencies, 32(1), 26-52.

Shah, R., Hayat, A., Zaman, M., \& Sabir, I. (2021). Youth Experiences of Violence at Home, School, and Street in Disadvantaged Urban Neighbourhoods of Islamabad, Pakistan: Troika of Violence. Deviant Behaviour, 1-14.

Tanyel, S. S., \& Kuralp, F. S. Ş. (2021). Tolerance for Sustainable Peace Culture in a Divided Society: The effect of Peace Education on Tolerance Tendency and Human Values. Social Indicators Research, 1-24.

Valenzuela, P. (2019). The values of peace in the Colombian Peace Agreement: discursive progress and empirical hurdles. Peacebuilding, 7(3), 297-313.

Verwoerd, W. B. (2019). Transforming Whiteness: Exploring Transformation at Stellenbosch University (Master's thesis, Faculty of Humanities).

Waldmüller, J. M., Jamali, H., \& Nogales, N. (2019). Operationalizing sustainable development goals in vulnerable coastal areas of Ecuador and Pakistan: Marginalizing human development? Journal of Human Development and Capabilities, 20(4), 468-485.

Yousaf, F. (2021). Jirga, Its Role and Evolution in Pakistan's Pashtun "Tribal" Society. In Clan and Tribal Perspectives on Social, Economic and Environmental Sustainability. Emerald Publishing Limited. 